PRE-PRINT MANUSCRIPT: NOT PEER REVIEWED

\title{
Changes in Physical Education Teachers' Motivations Predict the Evolution of Behaviors Promoting Students' Physical Activity During the COVID-19 Lockdown
}

\section{RUNNING HEAD: PHYSICAL EDUCATION TEACHERS AND COVID-19}

Silvio Maltagliati ${ }^{1}$, Attilio Carraro ${ }^{2}$, Géraldine Escriva-Boulley ${ }^{1,3}$, Maurizio Bertollo ${ }^{4}$, Damien Tessier ${ }^{1}$, Alessandra Colangelo ${ }^{5}$, Athanasios Papaioannou ${ }^{6}$, Selenia di Fronso ${ }^{4}$, Boris Cheval $^{7,8}$, Erica Gobbi ${ }^{9}$, Philippe Sarrazin ${ }^{1}$

${ }^{1}$ Univ. Grenoble Alpes, SENS, F-38000, Grenoble, France

${ }^{2}$ Faculty of Education, Free University of Bozen, Italy

${ }^{3}$ Haute Alsace University, Mulhouse, France

${ }^{4}$ Department of Medicine and Aging Sciences, University G. d'Annunzio of Chieti and Pescara, Chieti, Italy

${ }^{5}$ Department of Philosophy, Sociology, Education and Applied Psychology, University of Padova, Italy

${ }^{6}$ Department of Physical Education and Sport Sciences, University of Thessaly, Trikala, Greece

${ }^{7}$ Swiss Center for Affective Sciences, University of Geneva, Geneva, Switzerland

${ }^{8}$ Laboratory for the Study of Emotion Elicitation and Expression (E3Lab), Department of Psychology, University of Geneva, Geneva, Switzerland

${ }^{9}$ Department of Biomolecular Sciences, University of Urbino Carlo Bo, Urbino, Italy 
Corresponding authors: Silvio Maltagliati (Univ. Grenoble Alpes, Laboratoire SENS, UFRSTAPS, BP 5338041 Grenoble, France. E-mail: silvio.maltagliati@univ-grenoble-alpes.fr, @Maltagliati_s) ; Philippe Sarrazin (Univ. Grenoble Alpes, Laboratoire SENS, UFR-STAPS, BP 5338041 Grenoble, France. E-mail: philippe.sarrazin@univ-grenoble-alpes.fr ).

Words: 4898

Figures: 2

Tables: 2

Supplementary material: 3 Tables.

Please cite as: Maltagliati, S., Attilio, C., Escriva-Boulley, G., Bertollo, M., Tessier, D.,

Colangelo, A., Papaioannou, A., di Fronso, S., Cheval., B., Gobbi, E., Sarrazin, P. (2021). Changes in Physical Education Teachers' Motivations Predict the Evolution of Behaviors Promoting Students' Physical Activity During the COVID-19 Lockdown. SportRxiv. https://doi.org/ 10.31236/osf.io/h4mw8.

All authors have read and approved this version of the manuscript. 


\begin{abstract}
To promote students' physical activity (PA) during the COVID-19 lockdown, Physical Education (PE) teachers invested an unprecedented effort. This study identifies motivational determinants in changes in PE teachers' behaviors promoting PA. 931 Italian and French teachers' motivational determinants and behaviors promoting PA were measured, regarding before and during lockdown. Increased autonomous, controlled motivation, self-efficacy, perceived usefulness toward digital technologies and decreased amotivation were associated with an increased intention to promote PA. Increased intention, but also self-efficacy and perceived usefulness toward digital technologies, were associated with increased behaviors promoting PA. Implications regarding the investment of teachers in challenging situations are discussed.
\end{abstract}

Keywords: Physical Education; COVID-19; Physical Activity; Motivation; Cross-Cultural. 


\section{Changes in Physical Education Teachers' Motivations Predict the Evolution of \\ Behaviors Promoting Students' Physical Activity During the COVID-19 Lockdown}

During the Spring 2020, in most countries around the world, lockdown measures were adopted to hinder the spread of the COVID-19 pandemic. One of the most striking influence of restrictive measures was the closure of schools, affecting 1.2 billion students worldwide (UNESCO, 2020). To maintain a pedagogical connection with their students, teachers from all fields had to adapt their pedagogical practices (Crawford et al., 2020). Specifically, Physical Education (PE) teachers faced a new challenge: to keep their students physically active, despite being deprived from their physical presence. This mission was of great importance as the benefits of physical activity (PA) during the lockdown were particularly emphasized in terms of both physical and mental health (Cheval et al., 2020). To this intent, in Italy and France, the countries in which the study was conducted, PE teachers paid special attention to the promotion of PA. Indeed, Gobbi et al., (2020) revealed, from before to during lockdown, an increase of behaviors supporting students' self-regulated PA. For instance, a higher frequency of behaviors encouraging students to be active, to set goals or to monitor their PA levels was observed. Yet, despite the massive effort needed from teachers to adapt their behaviors, this study did not examine the motivational determinants involved in such evolution of teachers' behaviors. To fill this gap, the present work provides a complementary analysis of this dataset. It aims at explaining changes in PE teachers' behaviors by testing an integrated model that encompasses several motivational determinants (Hagger, 2009). These variables were selected because of their purported connection with the lockdown context and because previous research had established their importance in explaining teachers' engagement in challenging teaching situations. Below, we will describe the motivational determinants included in the 
aforementioned model: intention, self-determined motivation, self-efficacy, perceived ease and usefulness toward digital technologies, and engagement at work.

\section{Intention to promote $\mathbf{P A}$}

In most of the socio-cognitive models, intention is assumed to directly orient actions toward or away from specific behaviors (Brand \& Cheval, 2019). For instance, according to the Theory of Planned Behavior (Ajzen, 1985), intention, defined as one's willingness to perform a certain behavior, is the most proximal determinant of behavior. In educational settings, empirical studies have used, , for instance, intention as an indicator of teachers' readiness to promote physically active classes (Martin \& Kulinna, 2004), to implement the Greek curriculum (Gorozidis \& Papaioannou, 2011), or to participate in educational innovations training (Gorozidis \& Papaioannou, 2014; 2016). Based on these theoretical perspectives and empirical findings, changes in PE teachers' intention to promote PA, from before to during lockdown, were used as the main determinant of changes in their behaviors.

\section{Self-determined toward promoting PA}

Key constructs of the Self-Determination Theory (e.g., Ryan \& Deci, 2017) can also be used to explain changes in teachers' intention to promote PA. Indeed, type of motivation represents a distal factor which influences the decision-making process of engaging or not in a certain behavior (see Hagger \& Chatzisarantis, 2016 for a conceptual discussion). Specifically, the Self-Determination Theory distinguishes autonomous, controlled motivation and amotivation, arranged within a continuum of motivation (Ryan \& Deci, 2017). Autonomous motivation refers to intrinsic (e.g., doing something because it is interesting and enjoyable) and identified (e.g., because it is personally important and valuable) regulations. By contrast, controlled motivation encapsulates introjected (e.g., to avoid feelings of guilt and shame) and external (e.g., to comply to official authorities) regulations. Amotivation corresponds to the lack of intention of doing the activity, or when people enact passively. In educational settings, 
autonomous motivation has been associated with optimal professional functioning and is assumed to energize teachers' willingness to engage in challenging teaching situations (Ryan \& Weinstein, 2009). Conversely, controlled motivation or amotivation may hinder persistence and creativity (Ryan \& Weinstein, 2009). In PE, autonomous motivation, but not controlled motivation, was associated with greater intention (Gorozidis \& Papaioannou, 2014; 2016) and persistence (Lam et al., 2010) in implementing educational innovations. In this perspective, we examined whether changes in teachers' autonomous and controlled motivation, and amotivation toward the promotion of PA, from before to during lockdown, were associated with changes in teachers' intention to promote PA.

\section{Self-efficacy toward promoting PA}

Regarding the disruption of traditional educational settings during lockdown, selfefficacy appeared as a good candidate in explaining changes in teachers' intention to promote PA. Derived from the social-cognitive theory (Bandura, 1986), self-efficacy, defined as beliefs about individuals' perceptions of their capabilities to plan and execute a specific behavior, was associated with adaptive outcomes in educational settings (e.g., greater willingness to adapt one's pedagogical behaviors, even in challenging situations) (see Zee \& Koomen, 2016 for a review). In PE, this adaptive influence of self-efficacy was also evidenced (Gorozidis \& Papaioannou, 2011; Martin \& Kulinna, 2004; Pan et al., 2013). For instance, higher selfefficacy was associated with greater intention to promote health among students (Pan et al., 2013). In this line, the association of changes in teachers' self-efficacy with changes in their intention to promote PA was examined. Moreover, as the social-cognitive theory assumes that self-efficacy has also the potential to directly influence behaviors (Bandura, 1986), the associations between changes in self-efficacy and changes in behaviors promoting PA were also investigated.

\section{Perceived usefulness and ease toward digital technologies}


During lockdown, traditional face-to-face pedagogical interactions became impossible and teachers could only provide their pedagogical contents using digital technologies (e.g., live visio-conferences or video tutorials) (Gobbi et al., 2020). Teachers' familiarity with digital technologies was therefore assumed to play a pivotal role in their ability to cope with this situation. In this line, the Technology Acceptance Model (Davis, 1989) posits that perceived usefulness and perceived ease toward digital technologies are related to teachers' intention to use such tools in education (Teo, 2012). Thus, changes in perceived usefulness and ease toward digital technologies, from before to during lockdown, were thought to explain changes in PE teachers' intention to promote PA.

\section{Engagement at work}

Because professional routines were greatly disrupted during lockdown, engagement at work was also expected to explain teachers' involvement in the challenge of promoting PA. Defined as "a positive fulfilling work-related state of mind characterized by vigor, dedication, and absorption" (Schaufeli \& Bakker, 2004, p74), engagement at work was paired with an increased effort in challenging situations, such as engaging in pedagogical innovations (Karavasilis \& Georgios, 2019). Although engagement at work may fluctuate, this construct can be considered as relatively stable over time (Bakker, 2014). The association of engagement at work with changes in the intention to promote PA, from before to during lockdown, was investigated.

\section{The current study}

Gobbi et al. (2020) showed that Italian and French PE teachers manifested an increase in behaviors promoting students' self-regulated PA, from before to during lockdown. The present work extends this first study by intending to identify the role of motivational determinants in PE teachers' readiness to take up the challenge of promoting PA during lockdown. 
Nine-hundred thirty-one Italian and French secondary-school PE teachers completed a questionnaire assessing motivational determinants and self-reported behaviors promoting PA. We proposed an integrated model which examined the associations of changes in several motivational determinants, from before to during lockdown, with changes in teachers' intention and behaviors promoting PA (Figure 1). We also tested whether these relations were equivalent among Italian and French teachers.

First, we hypothesized that an increase in intention (H1a) and in self-efficacy (H1b) would be directly associated with an increase in behaviors promoting PA. Second, we expected that that an increase in autonomous motivation (H2a), self-efficacy (H2b) toward promoting PA, perceived usefulness $(\mathrm{H} 2 \mathrm{c})$ and ease $(\mathrm{H} 2 \mathrm{~d})$ toward digital technologies would be associated with an increase in the intention to promote PA. By contrast, we predicted that an increase in controlled motivation (H2e) and in amotivation (H2f) would be associated with a decrease in the intention to promote PA. Finally, higher engagement at work was expected to be associated with an increase in the intention to promote PA (H2g). Direct associations between changes in these variables and changes in behaviors promoting PA were also explored.

\section{Methods}

\section{Participants and procedure}

Italian and French PE teachers were invited to complete an online 20-minute-long questionnaire. It was launched from the end of April to the end of May 2020, which corresponded to the schools closure period in France and Italy (see Gobbi et al., 2020 for an overview). Teachers were recruited through social networks and thanks to the support of national institutional authorities. All participants signed an online informed consent form. Ninehundred thirty-one participants fully completed the questionnaire (age $=46$ years; $41 \%$ of women), including 497 Italian teachers and 434 French teachers (Table 1). To allow research 
teams to work together, the questionnaire was originally developed in English, and subsequently translated in Italian and in French (see Table S1).

\section{Measures}

With the exception of engagement at work, all motivational determinants and selfreported behaviors promoting PA were captured in reference of both before and during lockdown. To reduce risk of comparison bias, in a first part of the questionnaire, the participants were asked to retrospectively provide information about the variables of interest before lockdown (e.g., This part of the questionnaire focuses on your behaviors and motivations before the lockdown period). In a subsequent second part of the questionnaire, the participants provided information about the variables of interest during lockdown (e.g., This part of the questionnaire focuses on your behaviors and motivations during the lockdown period). Engagement at work was assessed at the end of the questionnaire and did not refer to a specific time period.

\section{Behaviors promoting $P A$}

Behaviors promoting PA were captured using three items (Before/during lockdown, how often did/do you guide your students to participate in out-of-school; Before/during lockdown, how often did/do you help students to set goals to participate in regular outsideschool PA?; Before/during lockdown, how often did/do encourage your students to selfmonitor how much they exercise, in order to set goals for more exercise outside school?). In the absence of well-validated tools, these items were created because they were assumed to reflect key teachers' behaviors in supporting students' self-regulated out-of-school PA (Gobbi et al., 2020). Answers were given on a scale ranging from 1 (Never) to 5 (Always). Scores were averaged to compute a mean score $(\alpha=.82$ and .79 for before and during lockdown, respectively).

\section{Intention to promote $P A$}


Intention to promote PA was assessed using a two-item scale (Ajzen, 1985)

(Before/during the lockdown period, I plan/ned to promote out-of-school PA of my students; Before/during the lockdown period, I am/was determined to promote outside-school PA of my students). Answers were given of a seven-point scale, ranging from 1 (Totally disagree) to 7 (Totally agree). Scores were averaged to compute a mean score $(\alpha=.86$ and .87 for before and during lockdown, respectively).

\section{Self-determined motivation toward promoting PA}

Motivation to promote PA was assessed using a five-item scale based on the Work Tasks Motivation Scale for Teachers (Fernet et al., 2008). Participants reported the degree to which five statements reflected their motivation to promote PA before/during lockdown. To keep the questionnaire as short as possible and because single-item scales have been show to provide acceptable validity (Gogol et al., 2014), each type of regulation was captured using a single item: intrinsic (Because I found/find it pleasant), identified (Because it was/is important for me), introjected (Because if I hadn't done/don't to it, I would have felt/feel bad), external (Because my PE teacher's work demanded/demands it) and amotivation (I didn't/don't feel concerned because I thought/think that promoting out-of-school PA among my students was/is not a part of my job). Answers were given on a seven-point scale, ranging from 1 (Does not correspond at all) to 7 (Totally corresponds). Autonomous motivation was obtained by averaging scores on items related to intrinsic and identified regulations $(\alpha=.50$ and .70 for before and during lockdown, respectively), while controlled motivation was computed by averaging scores on items related to introjected and external regulations $(\alpha=.54$ and .66 for before and during lockdown, respectively).

\section{Self-efficacy toward promoting $P A$}

Self-efficacy to promote PA before and during lockdown was captured using a fouritem subscale (Gorozidis \& Papaioannou, 2011). Participants were asked to indicate their 
confidence in their ability to help their students in reference of four statements (To set goals for regular out-of-school exercise and accomplish them; To find ways to exercise out-ofschool; To find ways to exercise out-of-school, even those who were the most inactive ones; To monitor themselves on how much they exercise, so as to set goals for more exercise out-ofschool). Answers were given on a scale ranging from 1 (Not confident at all) to 7 (Absolutely confident). Scores were averaged to compute a mean score $(\alpha=.87$ and .86 for before and during lockdown, respectively).

\section{Perceived usefulness and perceived ease toward digital technologies}

Based on previous research (Teo, 2012), perceived usefulness and perceived ease toward digital technologies were both assessed using a single item: Before/during lockdown, to what extent did/do you think that digital technologies could be useful in promoting out-ofschool PA among your students? for perceived usefulness; Before/during lockdown to what extent did/do you feel confident in your ability to use digital technologies to promote out-ofschool PA among your students?; for perceived ease. Answers were given on a scale ranging from 1 (Not confident at all for perceived ease; Not useful at all for perceived usefulness;) to 7 (Absolutely confident for perceived ease; Absolutely useful for perceived usefulness).

\section{Engagement at work}

Engagement at work was measured using the nine-item Utrecht Work Engagement Scale (Schaufeli et al., 2006), which enables to assess three dimensions of work engagement, through three items each: vigor (e.g., At my job, I feel strong and vigorous), absorption (e.g. I am immersed in my work) and dedication (e.g., I am proud of the job that I do). Participants were asked to indicate how often they experienced the proposed statements about their work using a seven-point scale ranging from 1 (Never) to 7 (Every day). Scores were averaged to compute a mean score $(\alpha=.93)$.

\section{Statistical analysis}


In a first step, measurement invariance was examined using a multi-group confirmatory factor analyses (MCFA), in order to establish the comparability of measurement models across the Italian and French samples (Milfont \& Fischer, 2010). A step-up approach was adopted to examine different forms of invariance (i.e., configural, metric, scalar) (e.g., Vandenberg \& Lance, 2000). A baseline model was computed by gathering scores from Italian and French teachers and the expected relationships between each item and their latent factor were checked (i.e., configural invariance). Metric and scalar invariances were then respectively tested by constraining the factor loadings and intercepts of items to be the same across samples. The comparisons of Root Mean Square Error of Approximation ( $\triangle$ RMSEA) and in Comparative Fit Indexes $(\triangle \mathrm{CFI})$ were used to inspect the changes in goodness of fits across models. $\mathrm{A} \Delta \mathrm{CFI} \leq$ .01 and a $\triangle \mathrm{RMSEA} \leq .015$ indicate that the null hypothesis of invariance should not be rejected (Chen, 2007).

Then, residualized change scores were obtained by regressing scored variables during lockdown (e.g., intention to promote PA during the lockdown) on their respective variables before lockdown (e.g., intention to promote PA before the lockdown) (Zumbo, 1999). Residuals were saved and used as observed variables in subsequent analyses. In addition of reducing autocorrelated errors and regression toward the mean effects (Zumbo, 1999), this approach was chosen as it allowed to focus on changes in variables, from before to during lockdown (see Table S2 for comparisons and associations of scored variables, in reference of before and during lockdown). However, because this approach focuses on the relationships between changes in variables rather than between their levels, correlations between scored variables are also provided in Table S3.

The hypothetical model was then tested in path analysis and CFI and RMSEA were computed to examine the goodness of the models fit (Brown, 2006). An acceptable model fit is indicated by $\mathrm{CFI}>.90$ and RMSEA $<.08$. Modification indices were also inspected to improve 
the model, and meaningful associations were included. Finally, using multi-group analyses, we tested whether path coefficients between the different variables were invariant across countries, by comparing the fit of models with and without equality constraints. Assuming that the unconstrained model (i.e., in which paths were allowed to vary across samples) showed a better fit to the data than the constrained model, a step-by-step approach was planned to identify which paths differed and needed to be released across samples. All analyses were conducted using RStudio, and lavaan package was used to conduct MCFA and path analyses (Rosseel, 2012).

\section{Results}

Descriptive statistics including means, standard-deviations, ranges, Cronbach's alphas are provided in Table 1 and correlations between residualized scores are reported in Table 2.

Regarding measurement invariance across the Italian and French samples, the baseline model showed acceptable fit to the data $(\mathrm{CFI}=0.901$; RMSEA $=.064[90 \%$ Confidence Interval $(90 \mathrm{CI})=0.061 ; 0.067])$ supporting configural invariance (factors loadings are presented in Table S1). When constraining factors loadings and intercept of items across samples, we obtained $\Delta \mathrm{CFI}=.004, \Delta \mathrm{RMSEA}=.003$ for metric invariance, and $\Delta \mathrm{CFI}=.006$, $\triangle \mathrm{RMSEA}=.003$ for scalar invariance. These findings suggested that measurement invariance should not be rejected among the two samples (Cheung \& Rensvold, 2002).

The hypothetical model gathering residualized scores from the two samples showed poor fit to the data $(\mathrm{CFI}=0.950 ; \mathrm{RMSEA}=.079[90 \mathrm{CI}=0.057 ; 0.103]$. After the inspection of modifications indices, a direct path from perceived usefulness toward digital technologies to changes in behaviors promoting PA was added to the model, which then showed good fit to the data $(\mathrm{CFI}=0.992 ; \mathrm{RMSEA}=.035[90 \mathrm{CI}=0.000 ; 0.064])$.

Figure 2 shows the parameter estimates from this final model. Changes in amotivation $(\beta=-.25,95 \%$ Confidence Interval (95CI) [-.30; -.19], $p<.001)$, controlled motivation $(\beta=$ $.11,95 \mathrm{CI}[.04 ; .17], p=.001)$, autonomous motivation $(\beta=.25,95 \mathrm{CI}[.18 ; .32], p<.001)$ 
self-efficacy $(\beta=.23,95 \mathrm{CI}[.17 ; .30], p<.001)$, and perceived usefulness toward digital technologies $(\beta=.12,95 \mathrm{CI}[.06 ; .18], p<.001)$, from before to during lockdown, were associated with changes in the intention to promote PA. Changes in perceived ease toward digital technologies $(p=.713)$ and engagement at work $(p=.952)$ were not significantly associated with changes in the intention to promote PA. The model explained $30 \%$ of the variance in changes in the intention to promote PA.

Changes in intention $(\beta=.26,95 \mathrm{CI}[.21 ; .31], p<.001)$, in self-efficacy $(\beta=.28$, $95 \mathrm{CI}[.23 ; .33, p<.001)$, and in perceived usefulness toward digital technologies $(\beta=.14$, $95 \mathrm{CI}[.09 ; .19], p<.001)$ were positively associated with changes in behaviors promoting PA. The model explained 33\% of the variance in changes in behaviors promoting PA.

Next, multi-group analyses showed that the unconstrained model had a better fit than the constrained model $(\triangle \mathrm{CFI}=.03, \Delta \mathrm{RMSEA}=.00)$. According to changes in fit indices, only two path coefficients were identified as significantly different by country: the paths from changes in autonomous motivation to changes in intention and from changes in perceived usefulness toward digital technologies to changes behaviors. When released across samples in the final model, estimated parameters for the path between changes in autonomous motivation to changes in intention were $\beta=.14,95 \mathrm{CI}[.17 ; .29], p=.009$ for Italian teachers and $\beta=$ $.33,95 \mathrm{CI}[.25 ; .42], p<.001$ for French teachers. Estimated parameters for the path between changes in perceived usefulness toward digital technologies to changes in behaviors were $\beta=$ $.08,95 \mathrm{CI}[.02 ; .15], p=.010$ for Italian teachers and $\beta=.17,95 \mathrm{CI}[.10 ; .24], p<.001$ for French teachers.

\section{Discussion}

\section{Main findings}

By identifying motivational determinants involved in PE teachers' engagement in the challenge of promoting PA among students during lockdown, the present study sheds light on 
underpinning processes of teachers' adaptation to disruptive educational settings. From before to during lockdown, changes in PE teachers' amotivation, controlled and autonomous motivation, self-efficacy, and perceived usefulness toward digital technologies were associated with changes in their intention to promote PA. In turn, changes in their intention to promote PA, but also in self-efficacy and in perceived usefulness toward digital technologies, were related to changes in behaviors promoting PA. Overall, these relationships were similar among Italian and French teachers, although some small differences could be noted.

\section{The role of intention}

Changes in PE teachers' intention to promote PA were positively associated with changes in behaviors promoting PA. While previous empirical evidence was scarce and contrasted in PE settings (Martin \& Kulinna, 2004; Stanec, 2009), our results support the intention-behavior relationship (Ajzen, 1985). In this line, the intention to promote PA during lockdown may have relied on a well-elaborated decision, based upon a balance between the pros and the cons, which would explain this relationship with implemented behaviors. However, a change in intention only predicts a small-to-medium change in behaviors $(\beta=.26)$. In other words, a stronger intention to promote PA during lockdown does not automatically translate into increased behaviors promoting PA. Some teachers may have experienced difficulties in turning their intention into action, either because they lacked resources (e.g., lack of theoretical knowledge about the promotion of PA) or because they encountered obstacles (e.g., to create pedagogical supports while keeping children at home). Future research could aim to investigate underlying motivational processes which enable (or impede) teachers to turn intention into action, especially in such case of challenging teaching situations.

\section{The role of self-determined motivation}

Results showed that, from before to during lockdown, an increase in autonomous motivation (especially among French teachers) and in amotivation were associated with an 
increase and a decrease in the intention to promote PA, respectively. As proposed by the SelfDetermination Theory (Ryan \& Deci, 2017) and consistent with previous literature in PE (Gorozidis \& Papaioannou, 2014, 2016), these findings suggest that autonomous motivation fosters teachers' engagement in challenging situations. As exemplified by the increase of autonomous motivation from before to during lockdown (Table 1), some PE teachers may have considered the promotion of PA during this period as something particularly interesting or important, thereby committing themselves to the pursuit of this goal. Conversely, amotivation have impeded their willingness to invest effort in this challenge. This finding seems of concern as this unprecedented context may have created feelings of helplessness or resignation among teachers.

An increase in controlled motivation was related to an increase in the intention to promote PA. By contrast with existing research (Gorozidis \& Papaioannou, 2014), these results emphasize that, during lockdown, PE teachers who expressed greater change in external (e.g., to comply to educational authorities' instructions) or internal (e.g., feelings of guilt) pressure also reported stronger intention to promote PA. Indeed, during this period, as teachers from other fields, PE teachers may have been often solicited by their hierarchy to help their students to be physically active or may have felt guilty not maintaining a certain connection with their students, thereby generating controlled forms of motivations. Although controlled motivation may have such positive short-term effects, the persistence of relating behaviors may quickly vanish, especially when external pressures are no longer exerted (Ryan \& Deci, 2017).

\section{The role of self-efficacy}

Changes in self-efficacy toward the promotion of PA were positively associated with both changes in intention and in behaviors promoting PA. These findings align with previous literature which established that higher self-efficacy was associated with a greater tendency to engage in new challenging teaching situations (Zee \& Koomen, 2016). For instance, teachers 
with higher self-efficacy were to be more likely to experiment different teaching materials (McKinnon \& Lamberts, 2014) and exhibited greater willingness in adapting their pedagogical practices, even in challenging situations (Sandholtz \& Ringstaff, 2014). To counteract the disruption of traditional pedagogical practices, self-efficacy appears as an important factor in teachers' engagement in the challenge of promoting PA during lockdown.

\section{The role of perceived usefulness and ease toward digital technologies}

An increase in perceived usefulness toward digital technologies was associated with an increase in the intention to promote PA, but also directly with changes in behaviors promoting PA. This latter relationship was particularly pronounced among French teachers who seemed to be less familiar with these tools than Italian teachers (Table 1). This finding is in line with previous research showing that perceived usefulness toward these tools was related to teachers' intention (Teo, 2012), but also to their actual use in classrooms (Scherer et al., 2015). Because of distance teaching imposed during lockdown, digital technologies became indispensable to support students in being physically active, as indexed by the increased implementation of visio-conference live sessions or video tutorials (Gobbi et al., 2020).

However, our results did not support the expected association between changes in perceived ease toward digital technologies and in intention to promote PA. This finding stands in contrast with previous work which emphasized that teachers' perceived ease toward digital technologies played an important role in the use of such tools (Teo, 2012). This discrepancy could be accounted by the fact that, despite a more frequent use of digital technologies and the possibility to develop new skills during this period (e.g., to learn to create video tutorials), changes in perceived ease toward these tools, from before to during the lockdown, were not

sufficient to have an effect on the intention to PA (see the strong association between the variables before and during lockdown in Table S2).

\section{The role of engagement at work}


Engagement at work was not related to changes in the intention to promote PA. One possible explanation was that engagement at work energize individuals' global commitment, but does not focus on a particular behavior (Schaufeli et al., 2006; but see Sonnentag, 2017 for a discussion) and, thereby, does not affect the intention to accomplish a specific behavior.

\section{Strengths and limitations}

The present study has several strengths. First, a theoretically-driven approach was adopted to identify motivational determinants involved in changes in teachers' behaviors. Second, this study was based on a large sample composed of Italian and French teachers. After establishing measurement invariance in the two samples, this cross-cultural approach shed light on the similarities and differences in associations across teachers from these two countries. Third, although variables relating to the before-lockdown period were retrospectively assessed, the longitudinal design of the study allowed to model the changes in measured constructs. A well-suited statistic approach, combining residualized scores and path analysis, subsequently enabled to investigate the relationships between these changes. However, this study also presents several limitations which need to be acknowledged. First, behaviors promoting PA were self-reported and only provided a global overview of teachers' behaviors during the lockdown period. Indeed, they did not refer to other pedagogical objectives, that PE teachers could have pursued during the lockdown period (e.g., learning students new motor skills, such as juggling). Moreover, this work did not examine the actual influence of PE teachers' behaviors on students' PA levels. Second, to keep the questionnaire as short as possible, some variables (i.e., self-determined motivation, perceived usefulness and ease toward digital technologies) were assessed using a low number of items, thereby limiting the internal consistency of scores. Third, another limitation stems a selection bias in our sample: teachers who were the most satisfied with their work may have been more likely to participate in this study. Fourth, given the moderate part of variance explained by our model, other determinants 
may have contributed to explain teachers' engagement in the challenge of promoting PA, including interpersonal (e.g., number of children at home) or emotional factors (e.g., anxiety, depression).

\section{Practical implications}

While the COVID-19 lockdown has asked teachers from all fields a massive effort of adaptation, the present study draws important implications in better supporting professionals to cope with such an unprecedented context. First, promoting autonomous motivation and reducing amotivation may foster teachers' intention to engage in teaching challenges. In this perspective, satisfying the three basic psychological needs (i.e., autonomy, competence and relatedness) could foster autonomous motivation (Jansen in de Wal et al., 2014). For example, during lockdown, encouraging collaborative work and experience sharing between colleagues, could have fulfilled teachers' relatedness and competence needs. In the same perspective, providing teachers with a rationale about their role during this period and reinforcing their capacity for choices (e.g., pedagogical supports, type of activities) could have satisfied their need for autonomy. Second, underlining prior mastery experiences (e.g., encouraging teachers to collect feedbacks about their students' experiences), enabling vicarious experiences (i.e., learning through the observation of another teacher), promoting verbal persuasion by giving positive feedbacks, and ensuring positive emotional state could represent insightful levers in supporting teachers' self-efficacy (Martin et al., 2009). Finally, in the context of distance teaching, educating teachers to the possibilities of digital technologies could reinforce their perceived usefulness toward these tools, which may, in turn, foster the implementation of renewed pedagogical practices (Scherer \& Teo, 2019). For instance, previous work proposed to train teachers to digital technologies in authentic contexts (Brenner \& Brill, 2016).

\section{Conclusion}


This study advances literature by contributing to understand why teachers engage in challenging situations, such as promoting PA during lockdown. We hope that it will help researchers and practitioners to better understand how to cope with disruptive educational settings and that these findings will ultimately contribute to the recognition of the important investment of PE teachers in an unprecedented context. 


\section{References}

Ajzen, I. (1985). From Intentions to Actions: A Theory of Planned Behavior. In J. Kuhl \& J. Beckmann (Eds.), Action Control (pp. 11-39). Springer Berlin Heidelberg. https://doi.org/10.1007/978-3-642-69746-3_2

Bakker, A. B. (2014). Daily fluctuations in work engagement: An overview and current directions. European Psychologist, 19(4), 227-236. https://doi.org/10.1027/1016$9040 / \mathrm{a} 000160$

Bandura, A. (1986). Social foundations of thought and action. Englewood Cliffs, NJ, 1986.

Brand, R., \& Cheval, B. (2019). Theories to Explain Exercise Motivation and Physical Inactivity: Ways of Expanding Our Current Theoretical Perspective. Frontiers in Psychology, 10, 1147. https://doi.org/10.3389/fpsyg.2019.01147

Brenner, A. M., \& Brill, J. M. (2016). Investigating Practices in Teacher Education that Promote and Inhibit Technology Integration Transfer in Early Career Teachers. TechTrends, 60(2), 136-144. https://doi.org/10.1007/s11528-016-0025-8

Brown, T. A. (2006). Confirmatory factor analysis for applied research. Choice Reviews Online, 44(05), 44-2769-44-2769. https://doi.org/10.5860/CHOICE.44-2769

Chen, F. F. (2007). Sensitivity of Goodness of Fit Indexes to Lack of Measurement Invariance. Structural Equation Modeling: A Multidisciplinary Journal, 14(3), 464-504. https://doi.org/10.1080/10705510701301834

Cheung, G. W., \& Rensvold, R. B. (2002). Evaluating Goodness-of-Fit Indexes for Testing Measurement Invariance. Structural Equation Modeling: A Multidisciplinary Journal, 9(2), 233-255. https://doi.org/10.1207/S15328007SEM0902_5

Cheval, B., Sivaramakrishnan, H., Maltagliati, S., Fessler, L., Forestier, C., Sarrazin, P., Orsholits, D., Chalabaev, A., Sander, D., Ntoumanis, N., \& Boisgontier, M. P. (2020). Relationships between changes in self-reported physical activity, sedentary behaviour 
and health during the coronavirus (COVID-19) pandemic in France and Switzerland. Journal of Sports Sciences, 1-6. https://doi.org/10.1080/02640414.2020.1841396

Crawford, J., Butler-Henderson, K., Jurgen, R., Malkawi, B. H., Glowatz, M., Burton, R., Magni, P., \& Lam, S. (2020). COVID-19: 20 countries' higher education intra-period digital pedagogy responses. Journal of Applied Learning \& Teaching, 3(1).

https://doi.org/10.37074/jalt.2020.3.1.7

Davis, F. D. (1989). Perceived usefulness, perceived ease of use, and user acceptance of information technology. MIS Quarterly: Management Information Systems, 13(3), 319339. https://doi.org/10.2307/249008

Fernet, C., Sencal, C., Guay, F., Marsh, H., \& Dowson, M. (2008). The Work Tasks Motivation Scale for Teachers (WTMST). Journal of Career Assessment, 16(2), 256279. https://doi.org/10.1177/1069072707305764

Gobbi, E., Maltagliati, S., Sarrazin, P., di Fronso, S., Colangelo, A., Cheval, B., EscrivaBoulley, G., Tessier, D., Demirhan, G., Erturan, G., Yüksel, Y., Papaioannou, A., Bertollo, M., \& Carraro, A. (2020). Promoting Physical Activity during School Closures Imposed by the First Wave of the COVID-19 Pandemic: Physical Education Teachers' Behaviors in France, Italy and Turkey. International Journal of Environmental Research and Public Health, 17(24), 9431. https://doi.org/10.3390/ijerph17249431

Gogol, K., Brunner, M., Goetz, T., Martin, R., Ugen, S., Keller, U., Fischbach, A., \& Preckel, F. (2014). "My Questionnaire is Too Long!” The assessments of motivational-affective constructs with three-item and single-item measures. Contemporary Educational Psychology, 39(3), 188-205. https://doi.org/10.1016/j.cedpsych.2014.04.002

Gorozidis, G., \& Papaioannou, A. (2011). Teachers' self-efficacy, achievement goals, attitudes and intentions to implement the new Greek physical education curriculum. European Physical Education Review, 17(2), 231-253. 
https://doi.org/10.1177/1356336X11413654

Gorozidis, G., \& Papaioannou, A. G. (2014). Teachers' motivation to participate in training and to implement innovations. Teaching and Teacher Education, 39, 1-11. https://doi.org/10.1016/j.tate.2013.12.001

Gorozidis, G. S., \& Papaioannou, A. G. (2016). Teachers' achievement goals and selfdetermination to engage in work tasks promoting educational innovations. Learning and Individual Differences, 49, 46-58. https://doi.org/10.1016/j.lindif.2016.05.014

Hagger, M. S. (2009). Theoretical integration in health psychology: Unifying ideas and complementary explanations. In British Journal of Health Psychology (Vol. 14, Issue 2, pp. 189-194). https://doi.org/10.1348/135910708X397034

Hagger, M. S., \& Chatzisarantis, N. L. D. (2016). The Trans-Contextual Model of Autonomous Motivation in Education: Conceptual and Empirical Issues and MetaAnalysis. Review of Educational Research, 86(2), 360-407.

https://doi.org/10.3102/0034654315585005

Jansen in de Wal, J., den Brok, P. J., Hooijer, J. G., Martens, R. L., \& van den Beemt, A. (2014). Teachers' engagement in professional learning: Exploring motivational profiles. Learning and Individual Differences, 36, 27-36.

https://doi.org/10.1016/j.lindif.2014.08.001

Karavasilis, \& Georgios. (2019). Work satisfaction or burnout and their impact on innovative work behavior of Greek teachers. Journal of Contemporary Education, Theory \& Research, 3, 3-10. https://doi.org/10.5281/zenodo.3635027

Milfont, T., \& Fischer, R. (2010). Testing measurement invariance across groups: applications in cross-cultural research. International Journal of Psychological Research, 3(1), 111-130. https://doi.org/10.21500/20112084.857

Lam, S. F., Wing-yi, Cheng, R., \& Choy, H. C. (2010). School support and teacher motivation 
to implement project-based learning. Learning and Instruction, 20(6), 487-497. https://doi.org/10.1016/j.learninstruc.2009.07.003

Martin, J. J., \& Kulinna, P. H. (2004). Self-efficacy theory and the theory of planned behavior: Teaching physically active physical education classes. Research Quarterly for Exercise and Sport, 75(3), 288-297. https://doi.org/10.1080/02701367.2004.10609161

Martin, J. J., McCaughtry, N., Kulinna, P. H., \& Cothran, D. (2009). The impact of a social cognitive theory-based intervention on physical education teacher self-efficacy. Professional Development in Education, 35(4), 511-529. https://doi.org/10.1080/19415250902781814

McKinnon, M., \& Lamberts, R. (2014). Influencing Science Teaching Self-Efficacy Beliefs of Primary School Teachers: A longitudinal case study. International Journal of Science Education, Part B: Communication and Public Engagement, 4(2), 172-194.

https://doi.org/10.1080/21548455.2013.793432

Pan, Y. H., Chou, H. S., Hsu, W. T., Li, C. H., \& Hu, Y. L. (2013). Teacher Self-Efficacy and Teaching Practices in the health and physical education curriculum in Taiwan. Social Behavior and Personality, 41(2), 241-250. https://doi.org/10.2224/sbp.2013.41.2.241

Rosseel, Y. (2012). Lavaan: An R package for structural equation modeling. Journal of Statistical Software, 48(1), 1-36. https://doi.org/10.18637/jss.v048.i02

Ryan, R., \& Deci, E. (2017). Self-determination theory. Basic psychological needs in motivation, development and wellness. Guilford Publications.

Ryan, R. M., \& Weinstein, N. (2009). Undermining quality teaching and learning: A selfdetermination theory perspective on high-stakes testing. Theory and Research in Education, 7(2), 224-233. https://doi.org/10.1177/1477878509104327

Sandholtz, J. H., \& Ringstaff, C. (2014). Inspiring Instructional Change in Elementary School Science: The Relationship Between Enhanced Self-efficacy and Teacher Practices. 
Journal of Science Teacher Education, 25(6), 729-751. https://doi.org/10.1007/s10972014-9393-0

Schaufeli, W. B., \& Bakker, A. B. (2004). Job demands, job resources, and their relationship with burnout and engagement: a multi-sample study. Journal of Organizational Behavior J. Organiz. Behav, 25, 293-315. https://doi.org/10.1002/job.248

Schaufeli, W. B., Bakker, A. B., \& Salanova, M. (2006). The Measurement of Work Engagement With a Short Questionnaire. Educational and Psychological Measurement, 66(4), 701-716. https://doi.org/10.1177/0013164405282471

Scherer, R., Siddiq, F., \& Teo, T. (2015). Becoming more specific: Measuring and modeling teachers' perceived usefulness of ICT in the context of teaching and learning. Computers \& Education, 88, 202-214. https://doi.org/10.1016/j.compedu.2015.05.005

Scherer, R., \& Teo, T. (2019). Unpacking teachers' intentions to integrate technology: A meta-analysis. Educational Research Review, 27, 90-109.

https://doi.org/10.1016/j.edurev.2019.03.001

Sonnentag, S. (2017). A task-level perspective on work engagement: A new approach that helps to differentiate the concepts of engagement and burnout. Burnout Research, 5, $12-$ 20. https://doi.org/10.1016/j.burn.2017.04.001

Stanec, A. D. S. (2009). The Theory of Planned Behavior: Predicting Teachers' Intentions and Behavior during Fitness Testing. Journal of Teaching in Physical Education, 28(3), 255271. https://doi.org/10.1123/jtpe.28.3.255

Teo, T. (2012). Examining the intention to use technology among pre-service teachers: An integration of the Technology Acceptance Model and Theory of Planned Behavior. Interactive Learning Environments, 20(1), 3-18.

https://doi.org/10.1080/10494821003714632

UNESCO. (2020). COVID-19 Educational Disruption and Response. COVID-19 Educational 
Disruption and Response.

Vandenberg, R. J., \& Lance, C. E. (2000). A Review and Synthesis of the Measurement Invariance Literature: Suggestions, Practices, and Recommendations for Organizational Research. Organizational Research Methods, 3(1), 4-70.

https://doi.org/10.1177/109442810031002

Zee, M., \& Koomen, H. M. Y. (2016). Teacher Self-Efficacy and Its Effects on Classroom Processes, Student Academic Adjustment, and Teacher Well-Being: A Synthesis of 40 Years of Research. Review of Educational Research, 86(4), 981-1015. https://doi.org/10.3102/0034654315626801

Zumbo, B. D. (1999). The simple difference score as an inherently poor measure of change: Some reality, much mythology. Advances in Social Science Methodology, 5, 269-304. 


\section{Figure 1.}

Hypothetical model.

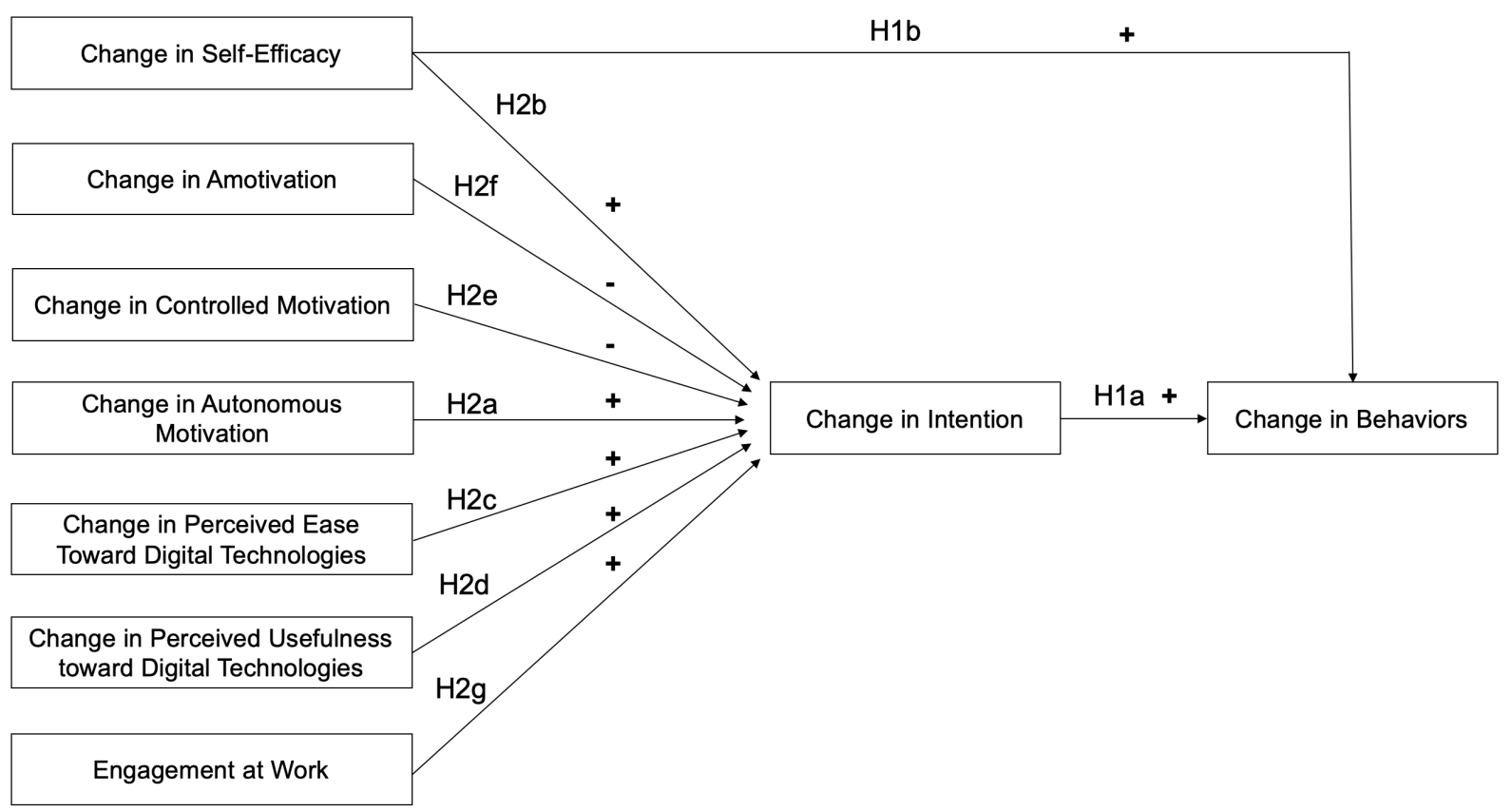




\section{Figure 2.}

Path diagram illustrating the associations of variables for Italian and French teachers.

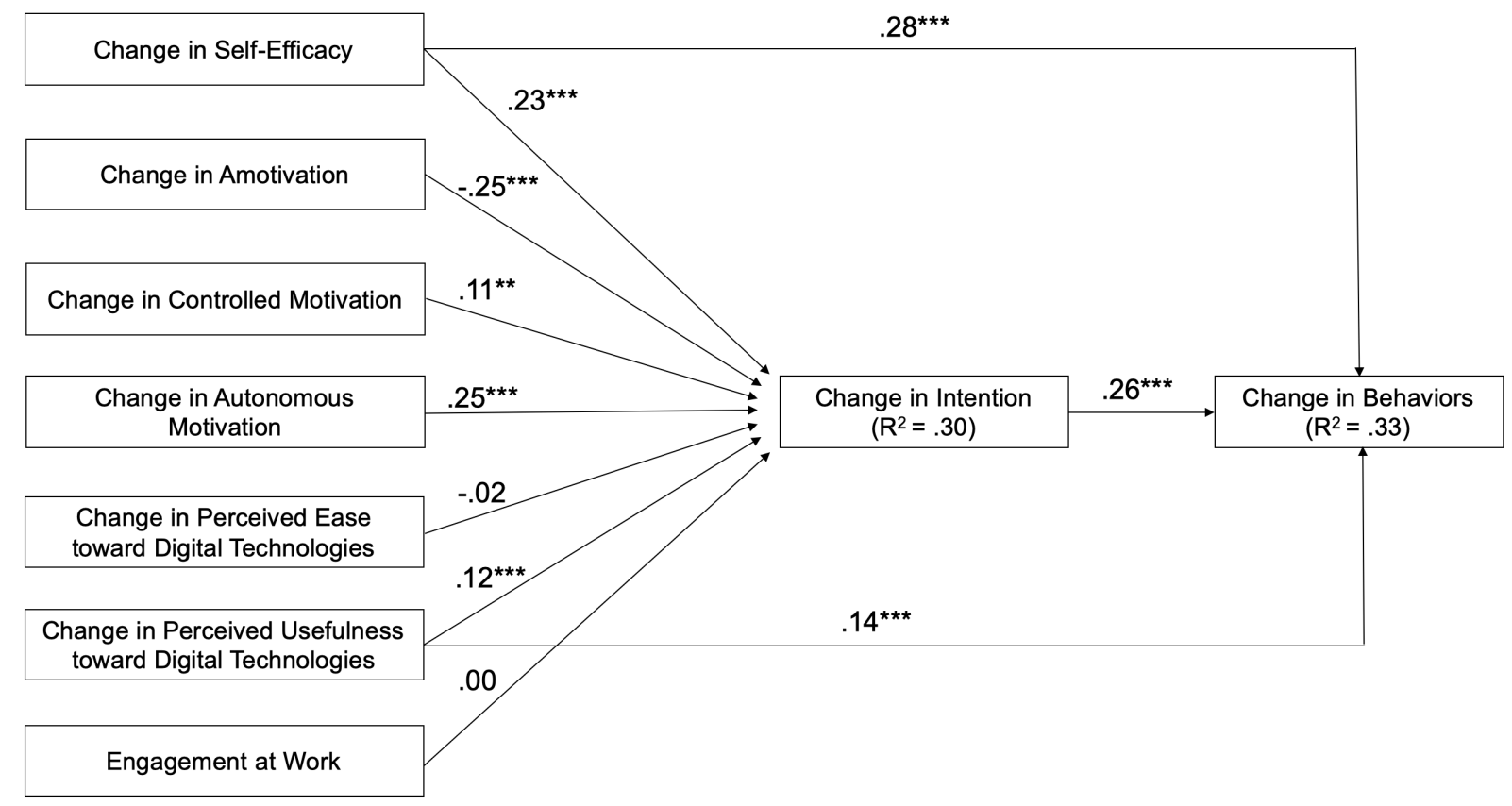

Note. Standardized beta coefficients $(\beta)$ and $\mathrm{R}$-squared $\left(\mathrm{R}^{2}\right)$ are presented. $* * *: p<.001 ; * *$ : $p<.01 ; *: p<.05$. 
Table 1. Descriptive statistics.

\begin{tabular}{|c|c|c|c|c|c|c|}
\hline & \multicolumn{3}{|c|}{ Italian Teachers $(n=497)$} & \multicolumn{3}{|c|}{ French Teachers $(n=434)$} \\
\hline & Mean (SD) & Range & $\alpha$ & Mean (SD) & Range & $\alpha$ \\
\hline Sex (\% of woman) & 67 & - & - & 49 & - & - \\
\hline Age (years) & $50(10)$ & $26-65$ & - & $42(12)$ & $22-64$ & - \\
\hline Years as PE teacher & $21(13)$ & $2-43$ & & $18(11)$ & $1-41$ & - \\
\hline \multicolumn{7}{|c|}{ Behaviors promoting PA } \\
\hline Before lockdown & $3.71(0.81)$ & $1-5$ & .84 & $2.92(0.80)$ & $1-5$ & .79 \\
\hline During lockdown & $3.78(0.89)$ & $1-5$ & .79 & $3.64(0.89)$ & $1-5$ & .80 \\
\hline \multicolumn{7}{|c|}{ Intention to promote $\mathbf{P A}$} \\
\hline Before lockdown & $5.34(1.62)$ & $1-7$ & .91 & $5.37(1.39)$ & $1-7$ & .82 \\
\hline During lockdown & $6.19(1.14)$ & $1-7$ & .87 & $6.14(1.09)$ & $1-7$ & .88 \\
\hline \multicolumn{7}{|c|}{ Amotivation to promote $\mathbf{P A}$} \\
\hline Before lockdown & $1.90(1.42)$ & $1-7$ & - & $1.47(0.98)$ & $1-7$ & - \\
\hline During lockdown & $1.62(1.25)$ & $1-7$ & - & $1.43(1.04)$ & $1-7$ & - \\
\hline \multicolumn{7}{|c|}{ Controlled motivation to promote PA } \\
\hline Before lockdown & $2.85(1.41)$ & $1-7$ & .47 & $3.49(1.63)$ & $1-7$ & .61 \\
\hline During lockdown & $5.02(1.50)$ & $1-7$ & .70 & $4.84(1.58)$ & $1-7$ & .61 \\
\hline \multicolumn{7}{|c|}{ Autonomous motivation to promote $\mathbf{P A}$} \\
\hline Before lockdown & $5.50(1.20)$ & $1-7$ & .46 & $4.94(1.30)$ & $1-7$ & .53 \\
\hline During lockdown & $5.84(1.09)$ & $1-7$ & .72 & $5.48(1.27)$ & $1-7$ & .67 \\
\hline \multicolumn{7}{|c|}{ Self-efficacy to promote $\mathbf{P A}$} \\
\hline Before lockdown & $5.27(1.14)$ & $1-7$ & .89 & $4.38(1.03)$ & $1-7$ & .84 \\
\hline During lockdown & $5.34(1.24)$ & $1-7$ & .85 & $4.47(1.22)$ & $1-7$ & .88 \\
\hline \multicolumn{7}{|c|}{ Perceived usefulness toward digital technologies } \\
\hline Before lockdown & $4.27(1.50)$ & $1-7$ & - & $3.96(1.54)$ & $1-7$ & - \\
\hline During lockdown & $5.44(1.57)$ & $1-7$ & - & $5.49(1.55)$ & $1-7$ & - \\
\hline \multicolumn{7}{|c|}{ Perceived ease toward digital technologies } \\
\hline Before lockdown & $4.42(1.49)$ & $1-7$ & - & $4.19(1.70)$ & $1-7$ & - \\
\hline During lockdown & $4.87(1.40)$ & $1-7$ & - & $4.72(1.60)$ & $1-7$ & - \\
\hline Engagement at work & $6.12(0.94)$ & $1-7$ & .95 & $5.75(0.89)$ & $1.4-7$ & .89 \\
\hline
\end{tabular}

Note: Means, standard-deviations (SD), ranges, Cronbach coefficients $(\alpha)$ are reported. 
Table 2. Correlations of residualized scores.

\begin{tabular}{|c|c|c|c|c|c|c|c|c|c|}
\hline & 1. & 2. & 3. & 4. & 5. & 6. & 7. & 8. & 9. \\
\hline 1. Behaviors promoting PA & - & $.45^{* * *}$ & $-.17 * * *$ & $.17 * * *$ & $.30 * * *$ & $.46^{* * *}$ & $.30 * * *$ & $.18 * * *$ & $.13^{* * *}$ \\
\hline 2. Intention to promote PA & & - & $-.33 * * *$ & $.24 * * *$ & $.38 * * *$ & $.36^{* * *}$ & $.25^{* * *}$ & $.09 * *$ & $.13^{* * *}$ \\
\hline 3. Amotivation to promote PA & & & - & $-.09 * *$ & $-.19 * * *$ & -.06 & $-.17 * * *$ & $-.15 * * *$ & $-.07 *$ \\
\hline 4. Controlled motivation to promote PA & & & & - & $.29 * * *$ & $.23 * * *$ & $.11^{* *}$ & .04 & $.13 * * *$ \\
\hline 5. Autonomous motivation to promote PA & & & & & - & $.33 * * *$ & $.17^{* * *}$ & $.08^{*}$ & $.21^{* * *}$ \\
\hline 6. Self-efficacy to promote PA & & & & & & - & $.22 * * *$ & $.19 * * *$ & $.21 * * *$ \\
\hline 7. Perceived usefulness toward digital technologies & & & & & & & - & $.25 * * *$ & .03 \\
\hline 8. Perceived ease toward digital technologies & & & & & & & & - & .03 \\
\hline 9. Engagement at work & & & & & & & & & - \\
\hline
\end{tabular}

Note: Correlation coefficients between residualized scores for the whole sample are reported. ***: $p<.001 ;{ }^{* *}: p<.01,{ }^{*}: p<.05$. 